\title{
Conductivity of YBCO ceramics in a wide range of temperatures and hafnium impurities concentrations
}

\author{
S.V.Savich ${ }^{1}$, A.V.Samoilov ${ }^{1}$, A.L.Samsonik ${ }^{1}$, \\ V.N.Sukhov ${ }^{1}$, K.V.Tiutierieva ${ }^{1,2}$, A.I.Rusalovich ${ }^{1}$, \\ R.V.Vovk ${ }^{1,2}$, A.B.Boynik ${ }^{2}$, A.Chroneos ${ }^{3}$ \\ ${ }^{1}$ V.Karazin Kharkiv National University, \\ 4 Svobody Sq., 61022 Kharkiv, Ukraine \\ ${ }^{2}$ Ukrainian State Academy of Railway Transport, 7 Feyerbaha Sq., \\ 61050 Kharkiv, Ukraine \\ ${ }^{3}$ Faculty of Engineering and Computing, Coventry University, \\ 3 Gulson Str., Coventry CV1 2JH, United Kingdom
}

Received July 12, 2015

Conductivity of $\mathrm{Hf}$ doped $\mathrm{YBa}_{2} \mathrm{Cu}_{3} \mathrm{O}_{7-\delta}$ ceramics was studied in the work. It was shown that introduction of $\mathrm{Hf}$ additive leads to increase of amount of scattering effective centers of the normal carriers. Excessive conductivity of the samples studied in a wide temperature range obeys the exponential temperature dependence, and near $T_{c}$ satisfactorily described by the theoretical model of Aslamazov-Larkin. At the same time the $\mathrm{Hf}$ additive leads to significant increase of the temperature range of existence of the pseudogap anomaly in $a b$-plane.

Keywords: excess conductivity, 2D-3D crossover, coherence length, pseudogap, doping.

Исследована проводимость керамики $\mathrm{YBa}_{2} \mathrm{Cu}_{3} \mathrm{O}_{7-\delta}$ легированной Hf. Показано, что внесение примеси $\mathrm{Hf}$ приводит к возрастанию числа әффективных центров рассеяния нормальных носителей. Избыточная проводимость исследованных образцов в широком интервале температур подчиняется экспоненциальной температурной зависимости, вблизи $T_{c}$ удовлетворительно описывается теоретической моделью Асламазова-Ларкина. При этом добавка $\mathrm{Hf}$ приводит к значительному расширению температурного интервала существования псевдощелевой аномалии в $a b$-плоскости.

Провідність ҮВаСиО керамік у широкому інтервалі температур і концентрацій домішок гафнію. С.В.Савич, О.В.Самойлов, О.Л.Салсонік, В.М.Сухов, К.В.Тютєрєва, А.І.Русалович, Р.В.Вовк, А.Б.Бойнік, О.Хронеос.

Досліджено провідність керамік $\mathrm{YBa}_{2} \mathrm{Cu}_{3} \mathrm{O}_{7-\delta}$ легованих Hf. Показано, що внесення домішки $\mathrm{Hf}$ приводить до зростання числа ефективних центрів розсіювання нормальних носіїв. Надлишкова провідність досліджених зразків у широкому інтервалі температур підпорядковується експоненційній температурній залежності, поблизу $T_{c}$ задовільно описується теоретичною моделлю Асламазова-Ларкіна. При цьому добавка $\mathrm{Hf}$ приводить до значного розширення температурного інтервалу існування псевдощілинної аномалії в $a b$-площині.

\section{Introduction}

As it is well known $[1,2]$, one of the most important aspects of technological ap- plications of high-temperature superconducting (HTSC) - materials is to ensure the sustainability of their oxygen subsystem. Mostly it 
relates to high-temperature superconducting compounds, so called 1-2-3 system or $\mathrm{ReBa}_{2} \mathrm{Cu}_{3} \mathrm{O}_{7-\delta}(\mathrm{Re}-\mathrm{Y}$ or lanthanides). Such compounds have a sufficiently high critical temperature $\left(T_{c}\right)$, which exceeds the temperature of liquid nitrogen [3], and have a high current carrying capacity in superconducting and normal states [4-6]. At the same time the presence of labile components in the system $[7,8]$ often contributes to the non-equilibrium state [9, 10 ], which can be relatively easily induced by application of high pressure [11, 12], abrupt changes in temperature [12, 14] or can occur during long-term storage or exploitation $[15,16]$ in other words aging. This in turn can change quite significant the critical parameters and conductive characteristics of the compound $[17,18]$.

One of the characteristic features of HTSC, compounds of the 1-2-3 system, is relative simplicity of full or partial substitution of components by their isoelectronic analogues [19-21]. As it was established in a number of studies [15, 17, 18] such a substitution often facilitates slowing of the aging processes in the compounds of such a type and improving the stability of their technological characteristics. The most clearly it is demonstrated in the case of ceramic samples, which are also currently the most functional in terms of their practical application [1].

At the same time, this kind of substitution often leads to significant evolution of specific physical phenomena observed in the high-temperature superconductors - materials in the normal (non-superconducting) state. These include the pseudogap (PG) [22, 23] and fluctuation [24, 25] anomalies, transitions of the type of metal-insulator [26, 27], non-coherent electric transport [28, 29], anisotropy of a number of physical characteristics $[30,31]$ etc. According to the modern concepts these unusual effects can play a key role in understanding of the nature of the high-temperature superconductivity. Given the above, in the present work we investigated an effect of Hf-impurities on the conductivity of HTSC - ceramics $\mathrm{YBaCuO}$ at temperatures near or above the critical value.

\section{Experimental}

Samples of $\mathrm{YBa}_{2} \mathrm{Cu}_{3} \mathrm{O}_{7-\delta}$ ceramics were synthesized by interaction of $\mathrm{Y}_{2} \mathrm{O}_{3}, \mathrm{BaCO}_{3}$, and $\mathrm{CuO}$ (all OS grades) compounds taken in the respective molar ratios in the temperature range of $750-900^{\circ} \mathrm{C}$. Obtained powder

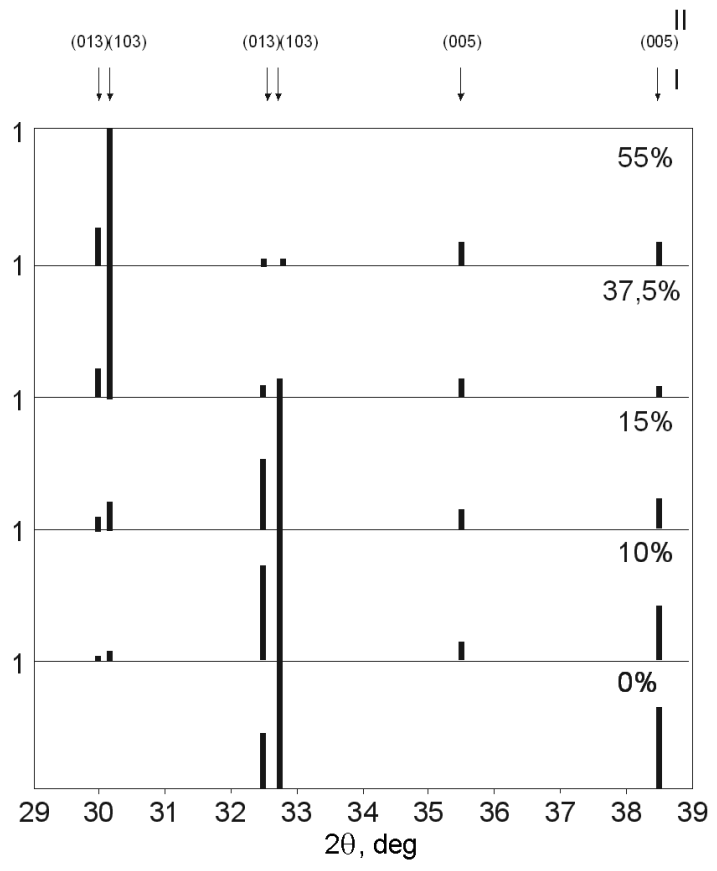

Fig. 1. Bar diagram of the relative intensities of X-ray diffraction peaks depending on content of hafnium oxide additives.

was pressed under pressure of 4 ton $/ \mathrm{cm}^{2}$ into disks of $20 \times 4 \mathrm{~mm}^{2}$ size and sintered at the temperature of $950-970^{\circ} \mathrm{C}$ within $5 \mathrm{~h}$ followed by cooling to the room temperature with intermediate dwell of $2-3 \mathrm{~h}$ at the temperatures of 890 and $530^{\circ} \mathrm{C}$. Obtained tablets represented superconducting ceramics with rhombic symmetry of lattice and $T_{c} \sim 90 \mathrm{~K}$. For obtaining samples with addition of hafnium the starting material was added with a various quantity of weight $\%$ of $\mathrm{Hf}_{2} \mathrm{O}_{3}$. Modes of production and saturation with oxygen were the same as for the undoped ceramics.

$\mathrm{X}$-ray studies of the structure and phase composition of the samples of $\mathrm{YBa}_{2} \mathrm{Cu}_{3} \mathrm{O}_{7-\delta}$ ceramic depending on hafnium additions were carried out using DRON-3 X-ray diffractometer in $\mathrm{Cu}-\mathrm{K} \alpha$-radiation. Profiles of the X-ray diffraction peaks were built by manual scanning with intervals of angles of $2 \theta=0.1^{\circ}$ in the background and with intervals of $2 \theta=0.02^{\circ}$ at maximum. Analysis of the obtained diffractograms showed that the initial sample had orthorhombic structure of perovskite type with the following lattice parameters: $a=3.8348 \AA, \quad b=3.8895 \AA$, $c=11.6790 \AA$, which corresponds to the literature data. With increasing content of $\mathrm{Hf}_{2} \mathrm{O}_{3}$ hafnium oxide additives the intensity of the X-ray diffraction peaks correspond- 
Table 1. Phase composition and lattice parameters of (YBaCuO $+\mathrm{Hf}$ ) ceramics (CuK-radiation), Angstrom (̊)

\begin{tabular}{|c|c|c|c|c|c|c||}
\hline Phases & Axis & $0 \%$ & $10 \%$ & $15 \%$ & $20 \%$ & $30 \%$ \\
\hline $\mathrm{YBa}_{2} \mathrm{Cu}_{3} \mathrm{O}_{7}$ & $a$ & 3.8348 & 3.8348 & $3 ., 8348$ & 3.8576 & 3.8433 \\
& $b$ & 3.8895 & 3.8895 & 3.8925 & 3.9163 & 3.8837 \\
& $c$ & 11.679 & 11.672 & 11.682 & 11.615 & 11.685 \\
& & 0 & 5 & 5 & 0 & 0 \\
\hline $\mathrm{II}$ & $a$ & & 4.1380 & 4.1594 & 4.1630 & 4.1523 \\
& $b$ & & 4.1739 & 4.2718 & 4.2295 & 4.2679 \\
& $c$ & & 12.633 & 12.650 & 12.643 & 12.636 \\
$\mathrm{Phases}$ & Axis & $32.50 \%$ & $37.50 \%$ & $50 \%$ & $52.50 \%$ & $55 \%$ \\
\hline $\mathrm{YBa}_{2} \mathrm{Cu}_{3} \mathrm{O}_{7}$ & $a$ & 3.8605 & 3.8691 & 3.8633 & 3.8604 & 3.8462 \\
& $b$ & 3.9014 & 3.9133 & 3.9314 & 3.9043 & 3.9133 \\
& $c$ & 11.668 & 11.647 & 11.677 & 11.647 & 11.630 \\
\hline
\end{tabular}

ing to the initial structure is reduced and diffraction peaks corresponding to the orthorhombic structure perovskite of type appear in the X-ray diffractograms but with higher parameters of the lattice.

\section{Results and discussion}

Table 1 shows the lattice parameters values depends on content of the additives. Fig. 1 shows part of a bar chart of the relative intensities of the X-ray diffraction peaks depending on the content of hafnium oxide additives. It is seen from the figure that with increasing the additives content of changes the phase composition of the samples. Amount of the initial orthorhombic phase is reduced and the orthorhombic phase with the larger lattice parameters increases. In the diffraction pattern of the sample with the maximum content of hafnium oxide $(55 \%)$ the only traces of the original structure were observed.

For resistive studies the pieces of rectangular shape were sawed from the "tablets".
Contacts were applied by rubbing of ceramic India into the surface followed by soldering of copper conductors to these sites. The electrical resistivity was measured by standard 4 contact procedure with direct current up to $10 \mathrm{~mA}$. The sample temperature was determined by platinum thermal resistor.

Temperature dependences of the stated electrical resistance of $R / R_{300}(T)$ samples are shown in Fig. 2. Resistive transitions into the superconducting state of the same samples are shown in the inset. It appears that the dependences are quasimetallic. Parameters of the studied samples are shown in the Table 2. According to the literature data the high values of $T_{c}=92.1 \mathrm{~K}$ critical temperature correspond to oxygen content $\delta \leq 0.1$ [35].

As appears from the Fig. $1 R / R_{300}(T)$ deviation from linear dependence takes place with the decrease of temperature below a certain characteristic value of $T^{*}$ which shows the appearance of the certain excess conductivity, which according to the theo-

Table 2 .

\begin{tabular}{|c|c|c|c|c|c|c|c||}
\hline \hline Sample & $\%$ Hf & $T_{c}, \mathrm{~K}$ & $T^{*}, \mathrm{~K}$ & $\Delta^{*}{ }_{a b}, \mathrm{meV} \ln ($ epsilonBB & $\varepsilon_{0}$ & $\xi_{c}(0), \AA$ \\
\hline K1 & 0 & 91.47 & 154 & 100.12 & -2.87 & 0.0567 & 1.39297 \\
K2 & 5 & 91.62 & 160 & 68.37 & -1.98 & 0.13807 & 2.17372 \\
K3 & 10 & 89.5 & 165 & 67.14 & -1.84 & 0.15882 & 2.33134 \\
K4 & 15 & 91.65 & 250 & 58.41 & -1.714 & 0.18014 & 2.48294 \\
K5 & 20 & 90.17 & 240 & 30.65 & -1.05 & 0.34994 & 3.4606 \\
\hline
\end{tabular}




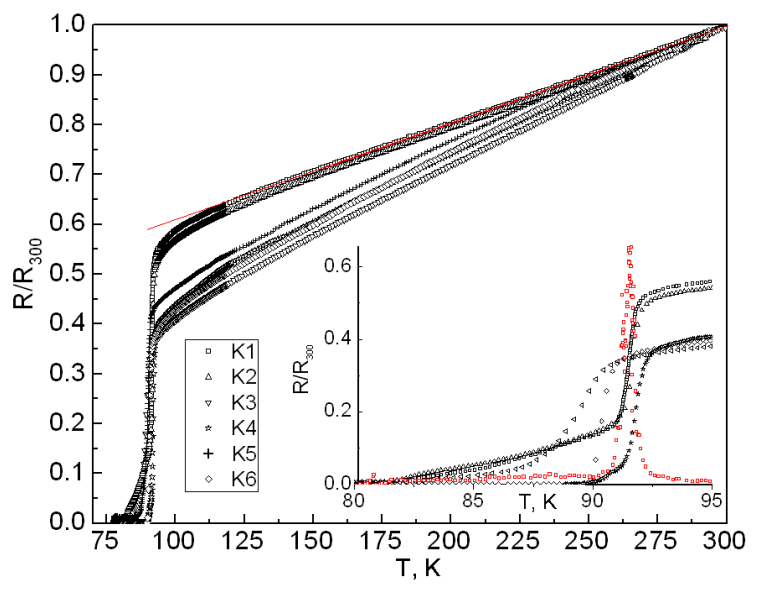

Fig. 2. Dependences of reduced electrical resistance $R / R_{300}(T)$ of ceramic samples with addition of $\mathrm{K} 1-\mathrm{K} 6$ hafnium. The inset shows transition to the superconducting state in coordinates of $R / R_{300}(T)$ and $\quad d\left(R / R_{300}(T)\right) / d T-T$ the area of superconducting transition of one sample. Numbering of the curves in the inset corresponds to the numbering in the Fig.

retical concepts due to the transition to the pseudogap regime $[22,23,36,37]$. Currently, the literature extensively discusses two basic scenarios the emergence of the pseudogap anomalies in the HTSC systems. Firstly, the emergence of the PG due to fluctuations in the short-range order "dielectric" type takes place at underdoped compositions (see. Eg [22, 36]). The second scenario involves the formation of the Cooper pairs at temperatures significantly above the critical $T^{*}>>T_{c}$ followed by the establishment of their phase coherence at $T^{*}$ $<T_{c}[23,37]$.

As seen from the Table and Fig. 1, with increase of the hafnium addition the linear region according $\rho_{a b}(T)$ substantially narrows as compared with the unalloyed sample and the temperature $T^{*}$ is shifted toward the higher temperatures up to $100 \mathrm{~K}$. This, in turn, indicates a corresponding expansion temperature range in which there exists excess conductivity.

Temperature dependence of the excess conductivity is usually determined by the equation:

$$
\Delta \sigma=\sigma-\sigma_{0}
$$

where $\sigma_{0}=\rho_{0}^{-1}=(A+B T)^{-1}$ is conductivity determined by interpolation of the linear section of $\rho(T)$ to the zero value of the temperature and $\sigma=\rho^{-1}$ is the experimentally determined value of conductivity in the normal condition. The experimental depend-

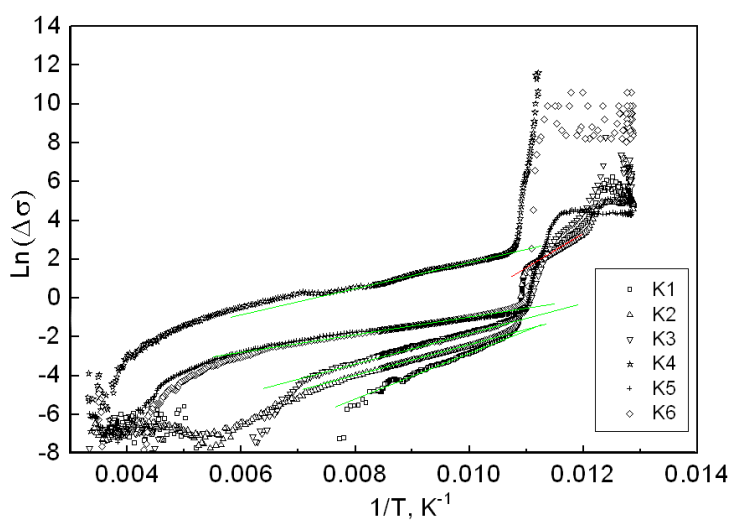

Fig. 3. Temperature dependences of excess conductivity of samples $\mathrm{K} 1-\mathrm{K} 6$ in coordinates of $\ln (\Delta \sigma)-1 T$. Designation curves refer to Fig. 2 . Straight lines shows approximation of Eq. (2), and insert - straight line with a slope $\operatorname{tg} \alpha_{1} \approx-0.5$ (3D-mode) and $\operatorname{tg} \alpha_{2} \approx-1.0$ (2D-mode). Arrows show the point of $2 \mathrm{D}-3 \mathrm{D}$ crossover.

ences $\Delta \sigma(T)$ are shown in Fig. 3 in coordinates of $\ln \Delta \sigma-1 / T$. It is seen that in a sufficiently wide temperature range, these curves have form of the straight lines, which corresponds to the description of the exponential dependence of the form:

$$
\Delta \sigma \sim \exp \left(\frac{\Delta_{a b}^{*}}{T}\right),
$$

where $\Delta_{a b} *$ - value determined by some thermal activation process through the energy gap - "pseudogap".

The exponential dependence $\Delta \sigma(T)$ was observed previously in the single-crystal YBaCuO [38]. As it was shown in [38], approximation of the experimental data can be significantly enhanced by introducing the factor $\left(1-T / T^{*}\right)$. In this case, the excess conductivity is proportional to the carrier density of superconducting $n_{s} \sim\left(1-T / T^{*}\right)$ and inversely proportional to the number of the pairs $\sim \exp \left(-\Delta_{a b} * / k T\right)$ destroyed by thermal motion. Here $T^{*}$ is considered as a mean temperature of the superconducting transition, and the temperature range $T_{f}<T<T^{*}$ where there is the pseudogap state is determined by the stiffness of the order parameter phase, in turn, depends on oxygen deficiency or concentration of dopant element. The value of $\Delta^{*}$, obtained from (2) for our experimental samples, is shown in the Table. It can be seen that the doping with hafnium leads to significant reduction in the absolute value of the pseudogap (decrease of angle of the linear 


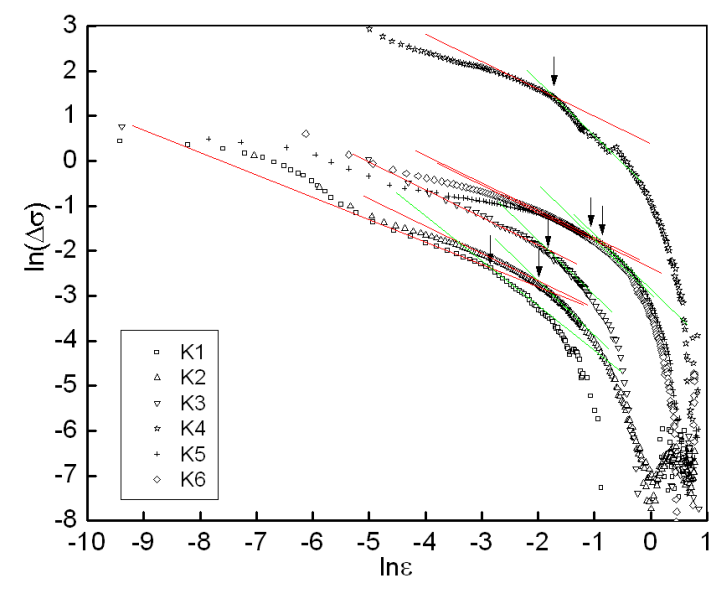

Fig. 4. Temperature dependences of excess conductivity of samples K1-K6 in $\ln \Delta \sigma-\ln \varepsilon$. Designation curves refer to Fig. 2. Straight lines shows approximation to the angle $\operatorname{tg} \alpha_{1} \approx-$ 0.5 (3D-mode) and $\operatorname{tg} \alpha_{2} \approx-1.0$ (2D-mode). Arrows show the point of $2 \mathrm{D}-3 \mathrm{D}$ crossover.

part of the curve), which also shows corresponding decrease in the ratio of $\rho(300) / \rho(0)$. This in turn can be indicative of increasing the number of active carriers of the scattering centers [10,37] as the content of $\mathrm{Hf}$ in the volume of the experimental sample.

As follows from Fig. 3, when we approach to the $T_{c}$ there is sharp increase in the value $\Delta \sigma$. From the theory [39] it is known that near $T_{c}$ there is an excess conductivity due process of fluctuation of pairing carriers. Their contribution to the conductivity at $T>T_{c}$ for two (2D) and three-dimensional (3D) cases is determined by the following power dependence:

$$
\begin{gathered}
\Delta \sigma_{2 D}=\frac{e^{2}}{16 \hbar d} \varepsilon^{-1}, \\
\Delta \sigma_{2 D}=\frac{e^{2}}{32 \hbar \xi_{c}(0)} \varepsilon^{-1 / 2},
\end{gathered}
$$

where $\varepsilon=\left(T-T_{c}\right) / T_{c}, e-$ electron charge, $\xi_{c}(0)-$ is coherence length along the $c$ axis at $T \rightarrow 0$ and $d$ is characteristic size of the two-dimensional layer. In our case $T_{c}$ was determined at the maximum point in the dependences of $d\left(R / R_{300}\right) / d T$ in the area of superconducting transition (Fig. 2, Inset).

Fig. 4 shows the temperature dependences of $\Delta \sigma(T)$ in $\ln \Delta \sigma-\ln \varepsilon$ coordinates. It can be seen that near $T_{c}$ these curves are approximated satisfactorily by the straight lines with a slope of $\operatorname{tg} \alpha_{1} \sim 0.5$ corresponding to the exponent parameter of $-1 / 2$ in

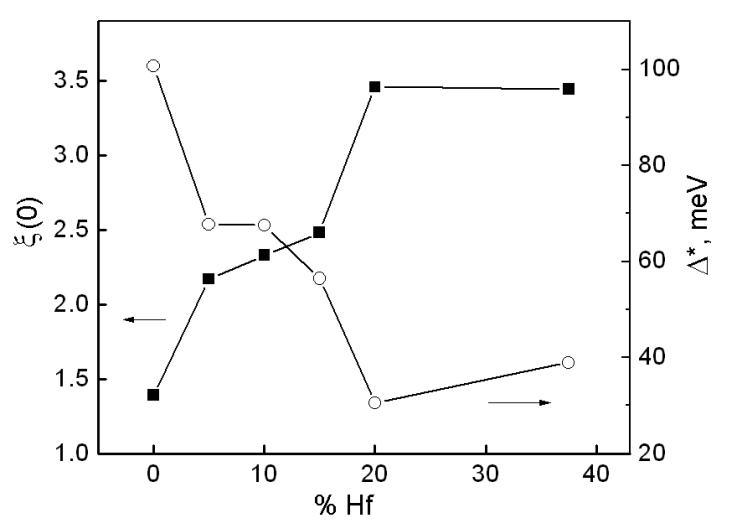

Fig. 5. Dependences of coherence length $\xi_{c}(0)$ and the value of $\Delta^{*}$ pseudogap on the percentage content of hafnium in the samples.

equation (4), which obviously evidences about 3D character of the fluctuation conductivity in this temperature interval. Upon further temperature increase the decrease rate $\Delta \sigma$ substantially increases $\left(\operatorname{tg} \alpha_{2} \sim 1\right)$ which in its turn can be interpreted as an indication for change of the fluctuation conductivity dimensionality. As it follows from Eqs. (3) and (4) at the point of 2D-3D crossover there is:

$$
\xi_{c}(0) \varepsilon_{0}^{-1 / 2}=d / 2
$$

In this case having determined $\varepsilon_{0}$ value and using the literature data on the dependence of interplane distance on $\delta[40,41]$ $(d \approx 11.7 \AA)$ it can be possible to calculate the values of $\xi_{c}(0)$. Fig. 5 shows the concentration dependence of the coherence length $\xi_{c}(0)$ and the value of $\Delta^{*}$ pseudogap on the percentage content of hafnium in the samples.

The made calculations showed that with introduction of $\mathrm{Hf}$ additives the change in the value of coherence length from $\xi_{c}(0)=$ $1.39 \AA$ in YBaCuO to $\xi_{c}(0)=3.44 \AA$ in the Hf doped samples takes place by $37.5 \%$ and 3D-2D crossover point significantly shifts with regard to the temperature (see Table 2 and Fig. 4, 5). Certain influence in this may have specific mechanisms of the quasiparticle scattering [42, 43], due to the presence in the system of kinematic and structural anisotropy.

\section{Conclusions}

In conclusion, we briefly sum up the main results obtained in this work. Excessive conductivity $\Delta \sigma(T)$ of Hf-doped YBaCuO samples in the wide temperature 
$T_{f}<T<T^{*}$ an exponential temperature dependence, and in the case near $T_{c}$ is satisfactorily described in the framework of theoretical model of Aslamazov-Larkin. Doping of YBaCuO single crystals by hafnium leads to the effect of expansion of the temperature range, the implementation of the PG-mode, thereby narrowing the area of the linear relationship $\rho(T)$ in $a b$-plane.

\section{References}

1. Z.Li, H.Wang, N.Yang et al., J.Chin.Ceram. Soc., 18, 555 (1990).

2. R.V.Vovk, N.R.Vovk, A.V.Samoilov et al., Solid State Commun., 170, 6 (2013).

3. M.K.Wu, J.R.Ashburn, C.J.Torng et al., Phys. Rev. Lett., 58, 908 (1987).

4. A.V.Bondarenko, V.A.Shklovskij, R.V.Vovk et al., Low Temp. Phys., 23, 962 (1997).

5. A.V.Bondarenko, V.A.Shklovskij, M.A.Obolenskii et al., Phys. Rev. B, 58, 2445 (1998).

6. A.V.Bondarenko, A.A.Prodan, M.A.Obolenskii et al., Low Temper. Phys., 27, 339 (2001).

7. J.D.Jorgencen, P.Shiyou, P.Lightfoot et al., Physica C, 167, 571 (1990).

8. R.V.Vovk, N.R.Vovk, O.V.Dobrovolskiy, J.Low Temper. Phys., 175, 614 (2014).

9. J.Kircher, M.Cardona, A.Zibold et al., Phys. Rev.B, 48, 9684 (1993).

10. R.V.Vovk, M.A.Obolenskii, A.A.Zavgorodniy et al., Low Temper. Phys., 33, 931 (2007).

11. S.Sadewasser, J.S.Schilling, A.P.Paulicas et al., Phys. Rev. B, 61, 741 (2000).

12. D.D.Balla, A.V.Bondarenko, R.V.Vovk et al., Low Temp. Phys., 23, 777 (1997).

13. R.Beyers, B.T.Ahu, G.Gorman et al., Nature, 340, 619 (1989).

14. M.A.Obolenskii, A.V.Bondarenko, R.V.Vovk et al., Low Temp. Phys., 23, 882 (1997).

15. D.A.Lotnyk, R.V.Vovk, M.A.Obolenskii et al., J. Low Temp. Phys., 161, 387 (2010).

16. R.V.Vovk, N.R.Vovk, G.Ya.Khadzhai et al., J. Mater. Sci: Mater. Electron., 25, 5226 (2014).

17. Q.-R.Feng, X.Zhu, S.-Q.Feng et al., Supercond.Sci.Technol., 6, 715 (1993).

18. R.V.Vovk, N.R.Vovk, O.V.Dobrovolskiy, $A d v$. Condens. Matter. Phys., 2013, 931726 (2013).
19. Physical Properties High Temperature Superconductors, ed. by D.M.Ginsberg, I.-Singapore, Word Scientific (1989).

20. A.Chroneos, I.L.Goulatis, R.V.Vovk, Acta Chim.Sloven., 54, 179 (2007).

21. R.V.Vovk, N.R.Vovk, G.Ya.Khadzhai et al., Solid State Commun., 190, 18 (2014).

22. M.V.Sadovskii, I.A.Nekrasov, E.Z.Kuchinskii et al., Phys. Rev. B, 72, 155105 (2005).

23. A.L.Solovjov, M.A.Tkachenko, R.V.Vovk et al., Physica C, 501, 24 (2014).

24. T.A.Friedman, J.P.Rice, J.Giapintzakis et al., Phys. Rev. B, 39, 4258 (1989).

25. R.V.Vovk, N.R.Vovk, G.Y.Khadzhai et al., Curr.Appl.Phys., 14, 1779 (2014).

26. K.Widdera, D.Bernera, H.P.Geserich et al., Physica C, 251, 274 (1995).

27. R.V.Vovk, Z.F.Nazyrov, I.L.Goulatis et al., Physica C, 485, 89 (2013).

28. R.V.Vovk, G.Ya.Khadzhai, O.V.Dobrovolskiy, Appl.Phys.A, 117, 997 (2014).

29. R.V.Vovk, N.R.Vovk, O.V.Shekhovtsov et al., Supercond. Sci. Technol., 26, 085017 (2013).

30. P.W.Anderson, Phys.Rev.Lett., 67, 2092 (1991).

31. R.V.Vovk, G.Ya.Khadzhai, O.V.Dobrovolskiy, Mod.Phys. Lett. B, 28, 1450245(2014).

32. J.Ashkenazi, J.Supercond.Nov.Magn., 24, 1281 (2011).

33. R.V.Vovk, M.A.Obolenskii, A.A.Zavgorodniy et al., Mod. Phys. Lett. B, 25, 2131 (2011).

34. M.Akhavan, Physica B, 321, 265 (2002).

35. P.Schleger, W.Hardy, B.Yang, Physica $C$, 176, 261 (1991).

36. A.V.Puchkov, P.Fournier, D.N.Basov et al., Phys. Rev. Lett., 77, 3212 (1996).

37. R.V.Vovk, G.Y.Khadzhai, O.V.Dobrovolskiy, Solid State Commun., 204, 64 (2015).

38. R.V.Vovk, A.A.Zavgorodniy, M.A.Obolenskii et al., Mod. Phys. Lett. B, 24, 2295 (2010).

39. L.G.Aslamazov, A.I.Larkin, Phys.Lett.A, 26, 238 (1968).

40. G.D.Chryssikos, E.I.Kamitsos, J.A.Kapoutsis et al., Physica C, 254, 44 (1995).

41. R.V.Vovk, M.A.Obolenskii, Z.F.Nazyrov, J. Mater Sci.:Mater. Electron., 23, 1255 (2012).

42. R.V.Vovk, C.D.H.Williams, A.F.G.Wyatt, Phys. Rev. B, 69, 144524 (2004).

43. D.H.S.Smith, R.V.Vovk, C.D.H.Williams et al., New J.Phys., 8, 128 (2006). 